\title{
Empreendedoras da forma. Mulheres, fisiculturismo e mercado fitness
}

\author{
Shape's entrepreneurs. Women, bodybuilding and fitness market
}

\section{Michelle Carreirão Gonçalves*}

\author{
Licenciada em Educação Física e \\ bacharel em Filosofia pela UFSC. \\ Mestre e Doutora em Educação \\ pela UFSC. Professora do Departa- \\ mento de Didática da Faculdade \\ de Educação da UFRJ. Pesquisa- \\ dora do Laboratório de Pesquisas \\ em Educação do Corpo (UFRJ) e \\ do Núcleo de Estudos e Pesquisas \\ Educação e Sociedade Contempo- \\ rânea (UFSC). \\ •michelle_carreirao@yahoo. \\ com.br \\ http://orcid.org/0000-0002- \\ 8350-2692
}

RECIBIDO: 7.7.2021

ACEPTAD0: 18.8.2021

\section{Resumo}

Em pesquisa realizada com atletas mulheres de fisiculturismo, buscando compreender como conformam suas subjetividades atléticas por meio da modificação corporal extrema, deparamo-nos com identidades marcadas por um sistema de códigos, discursos e práticas que incorporam ideais de sacrifício, superação, força, motivação, garra e potência que extrapolam o metier esportivo, alcançando a dimensão do mercado, do business, da concorrência encarnados nos corpos empreendedores, tanto no sentido da produção da modelação muscular quanto da venda de serviços a ela ligados. Assim, objetivamos, no presente artigo, apresentar as estratégias laborais de fisiculturistas que resultam, segundo nossa hipótese, de um tipo de subjetividade atlética que se expressa também em uma subjetividade empreendedora, estabelecendo um diálogo entre os campos competitivos e concorrenciais do esporte e do mercado. Para tanto, trabalhamos com os discursos de duas atletas brasileiras da modalidade por nós entrevistadas de maneira remota devido à pandemia da covid-19, analisando como esse esporte dialoga com os ideais do empreendedorismo a partir da inculcação da concorrência e do individualismo, não só na forma da competição, mas também da manutenção da vida, na geração e na venda de produtos e serviços ligados ao mercado fitness.

Palavras-chave: esporte, trabalho, mercado 


\section{Albstract}

In a research carried out with female bodybuilding athletes, seeking to understand how they shape their athletic subjectivities through extreme body modification, we came across identities marked by a system of codes, discourses and practices which incorporate ideals of sacrifice, resilience, strength, motivation, determination and power beyond the sports metier, reaching the dimension of the market, business, the competition incarnated in the bodies of entrepreneurs, both in terms of the production of muscle modeling and the sales of services related to it. Thus, in this article, we aim to present the work strategies of bodybuilders that result, according to our hypothesis, from a type of athletic subjectivity which is also expressed in an entrepreneurial subjectivity, establishing a dialogue between the competitive fields of sport and market. To do so, two Brazilian athletes of this sport were remotely interviewed, due to the COVID-19 pandemic. An analysis was made on how this sport dialogues with the ideals of entrepreneurship from the inculcation of competition and individualism, not only in the sphere of the sport competition, but also the maintenance of life, as well as the generation and sales of products and services related to the fitness market.

Keywords: sport, work, markets.

\section{Introdução}

O mercado dos cuidados com o corpo e a modelação corporal abrange uma infinidade de produtos e serviços, dos salões de beleza às academias de ginástica e musculação, dos centros estéticos aos consultórios nutricionais, das lojas de artigos naturais e suplementos alimentares às competições de crossfit. É um campo que movimenta tanto capital econômico como capital simbólico, no sentido bourdieusiano do termo. Se o corpo é um dos principais paradigmas modernos, como suporte de expressão de identidades, materialidade que faz de cada um ser o que é, dedicar tempo e dinheiro a ele (e nele) tornou-se prática comum.

Nesse cenário encontramos uma cultura da aptidão e da construção física que promete restituir a vitalidade do corpo, constituindo um campo denominado de fitness que dissemina discursos e práticas voltadas à saúde, à qualidade de vida, a o bem-estar e ao embelezamento. 0 fio condutor desse setor é o culto ao corpo, mobilizando um conjunto de "produtos, serviços e modos de ser", desde "exercícios, academias, alimentação, suplementos, dietas, bebidas, controle das emoções, eventos, conversas e aplicativos, até diversões, músicas, hábitos e modos de vestir, de comer, de socializar" (Schwengber et al., 2018, p. 1169). A cultura fitness expressa um ideário que responsabiliza o indivíduo por sua saúde e pelos cuidados de si mediados pela prática regular de exercício físico e 
alimentação equilibrada. Torna-se imperativo que cada um se engaje nesse projeto, tanto subjetivamente (motivando-se a iniciá-lo e o incorporando ao seu cotidiano) quanto objetivamente (pagando os custos monetários desse estilo de vida). É um investimento sobre si que exige um elevado custo em produtos e serviços, é a objetivação de uma mentalidade (ou discurso) em um mercado que se encontra em plena expansão.

Segundo dados da IHRSA (International Health Racquet \& Sportsclub Association, associação internacional dos líderes da indústria do fitness) publicados em 2018 e divulgados pela Associação Brasileira de Academias (ACAD Brasil), o setor alcançou, no ano anterior (2017), “cerca de 174 milhões de clientes, em 65 mercados, distribuídos por mais de 201 mil academias, com uma estimativa de resultados da ordem de 87,2 bilhões de Dólares" (ACAD Brasil, 2018, p. 10) no âmbito mundial. E a meta é seguir crescendo, atingindo, em 2030, 230 milhões de pessoas pelo globo. 0 Brasil ocupava a $12^{\mathrm{a}}$ posição no ranking de maior faturamento, mas a $2^{\underline{a}}$ em número de academias e a $4^{\mathrm{a}}$ em quantidade de clientes (todos os quadros liderados pelos EUA), o que mostra a significância desse mercado na cultura brasileira.

Nos últimos anos, notadamente a partir da década de 2000, vimos associar-se à cultura fitness aquilo que conhecemos como fisiculturismo, prática esportiva que se baseia na modelação corporal extrema por meio de musculação e dieta controlada. Gestado no interior dos gyms, o fisiculturismo se configura como um esporte não-oficial por não ter reconhecimento do Comitê Olímpico Internacional (COI), o que significa a proibição de disputas no âmbito dos eventos por ele promovidos (como os Jogos Olímpicos) e também a inexistência de uma federação que unifique as regras e a prática como um todo. 0 que se tem é um conjunto de instituições que possuem autonomia administrativa e poder decisório reconhecidos pelo Sistema Nacional de Desporto, no caso do Brasil, implicando na adoção de regulamentos e critérios de competição e avaliação conforme desejarem (Lima, 2017). Assim, há um mercado que se estabelece também no cenário dos campeonatos de fisiculturismo, disputando capital pecuniário (com afiliados e competições) e capital simbólico (de quem "dita as regras do jogo").

Apesar de sua autonomia como prática esportiva e sua anterioridade histórica em relação ao que conhecemos como cultura fitness - tendo o fisiculturismo se desenvolvido entre os anos 1930 e 1940, particularmente a partir de 1946, com a criação de sua primeira federação nos Estados Unidos (Lima, 2017), e as práticas fitness durante as décadas de 1970 e 1980, naquele mesmo país, associadas ao discurso médico e ao mercado de cuidados e modelação corporal (Landa, 2011) -, no início do século XXI, as grandes federações passaram a incluir o termo fitness em suas nomenclaturas como estratégia de popularização e de venda do esporte, unindo-o de forma mais clara à indústria da atividade física e saúde - a IFBB tornou-se International Federation of Bodybuilding and Fitness e a NABBA incorporou a sigla WFF (NABBA/WFF) gerando a National Amateur 
Body Building Association/World Fitness Federation. Nesse processo, a criação de categorias competitivas de fitness, além das de fisiculturismo, segmentou a modalidade em grupos mais comerciais e outros mais conectados à sua tradição (Lima, 2017), numa tentativa de torná-la mais palatável, vendável.

Em pesquisa realizada com atletas mulheres de fisiculturismo, buscando compreender como conformam suas subjetividades atléticas por meio da modificação corporal extrema, deparamo-nos com identidades marcadas por um sistema de códigos, discursos e práticas que incorporam ideais de sacrifício, superação, força, motivação, garra e potência que extrapolam o metier esportivo, alcançando a dimensão do mercado - entendido aqui como o "locus do encontro de duas forças independentes, oferta e demanda" (Gonçalves, 2012, p. 645) -, do business, da concorrência encarnados nos corpos empreendedores, tanto no sentido da produção da modelação muscular quanto da venda de serviços a ela ligados. Assim, objetivamos, no presente artigo, apresentar as estratégias laborais de fisiculturistas que resultam, segundo nossa hipótese, de um tipo de subjetividade atlética que se expressa também em uma subjetividade empreendedora, estabelecendo um diálogo entre os campos competitivos e concorrenciais do esporte e do mercado. Em ambos, cada indivíduo "tenta superar o outro numa luta incessante para tornar-se líder e como tal permanecer" (Carmo et al., 2021, p. 25).

Chegamos a essa questão a partir de entrevistas realizadas com três fisiculturistas selecionadas conforme seu tempo de prática e experiência em diferentes categorias do esporte - o intuito foi reunir atletas com padrões corporais distintos, tensionando as formas de produção desses corpos e os processos subjetivos a elas vinculados. Por conta da pandemia da covid-19, as conversas aconteceram de maneira remota, entre março e abril de 2020, via plataforma Jitsi Meet, gravadas em áudio com dispositivo externo, conforme permissão das entrevistadas, sendo posteriormente transcritas. Utilizamos um roteiro semiestruturado, o que permitiu que outras questões fossem exploradas ao longo do encontro virtual, para além daquelas anteriormente elaboradas e que versavam sobre histórico na modalidade, rotina de treinamento, dieta, suplementação e manipulação hormonal, competições, relações sociais, inserção das mulheres no fisiculturismo, projetos e expectativas esportivas, utilização e influência das redes sociais, feminilidade e representações sobre o corpo.

Para fins analíticos, categorizamos nossas informantes em: Iniciante (menos de 5 anos competindo), Experiente (entre 5 e 10 anos competindo) e Profissional (mais de 10 anos competindo e profissionalizada no esporte). Tendo em vista o escopo do presente artigo, trabalharemos com dados referentes apenas às duas últimas, pois a primeira, apesar de ter afirmado que deseja estudar para entrar "na área do esporte", ainda não se estabeleceu no mercado de trabalho fitness como a Experiente (40 anos, atleta do Rio de Janeiro/RJ, profissional de Educação Física atuando como professora de ginástica, instrutora de musculação e personal trainer, atleta amadora de fisiculturismo 
na categoria Women's Physique da IFBB) e a Profissional (44 anos, atleta do Rio de Janeiro/RJ, profissional de Educação Física atuando como personal trainer, foi atleta amadora de fisiculturismo de 2005 a 2011, tornou-se profissional da IFBB Pro (Liga Profissional da IFBB), em 2012, iniciou no esporte na categoria Wellness, passando pelas categorias Bodyfitness e Figure - as duas primeiras como amadora e a terceira como profissional -, e atualmente retornou para Wellness que se profissionalizou em 2019).

Nessa primeira aproximação, percebemos a tendência em seguir uma carreira que se vincule, de alguma maneira, ao esporte e ao mundo fitness, com a opção pela Educação Física. Esse dado sinaliza para uma mobilização do seu capital-corpo (Wacquant, 2002) - e de toda uma expertise aprendida para construí-lo - em direção à formação acadêmico-profissional, o que permite manter-se no mercado esportivo/fitness. 0 fato de serem atletas e terem um corpo milimetricamente modelado legitima suas práticas e angaria mais clientes, reafirmando a ideia de que ensinarão aquilo que supostamente sabem fazer, premissa comum na identidade de professores e profissionais de Educação Física (Vieira e Vaz, 2014).

Apresentamos então, nas próximas páginas, as estratégias empreendedoras incorporadas por essas mulheres atletas da forma física, tendo em conta suas representações e ações referentes ao mundo do trabalho, seja no campo do esporte, como fisiculturistas que disputam ganhos (não apenas de troféus, mas também de recursos, como patrocínios e produtos), seja no campo do fitness, como profissionais que atuam auxiliando outras pessoas (especialmente outras mulheres) a alcançarem o corpo tão desejado.

\section{Mercado do fisiculturismo: entre esporte, fitness e beleza}

O fisiculturismo é uma prática que exige elevado investimento financeiro. Da filiação nas federações à participação nos campeonatos, passando pelos gastos com academia, dieta, suplementação, hormônios, figurinos e tratamentos estéticos complementares, o montante de verba empregada é proporcional ao tempo e à dedicação dispensados na preparação e carreira atlética. Desde cedo, aprende-se que é um esporte caro, sem grandes retornos no âmbito das competições, mas que pode ser um meio para outras possibilidades, algo que nossas informantes parecem ter desenvolvido com perspicácia.

Antes de chegar em seus empreendimentos, vale olhar para a própria estrutura desse esporte que se estabelece como um mercado que transita entre o esportivo, o fitness e o da beleza, movimentando um conjunto de produtos e serviços no âmbito das competições. Tal dinâmica, cremos, ajuda a moldar um clima de consumo e de venda 
que pode impactar no delineamento dos projetos profissionais dessas atletas, conformando uma subjetividade que tenciona explorar as "capacidades empreendedoras individuais" numa estrutura de valorização de "livres mercados e livre comércio" (Harvey, 2005, p. 12).

Parece-nos que a ideia de concorrência já se apresenta na própria organização do esporte, com suas distintas federações que se articulam como grandes mercados. Estar em uma ou em outra obedeceria, aparentemente, o desejo e a vontade das atletas, reafirmando a ideia de liberdade para poder atuar onde e quando quiserem. Sobre isso, disse-nos a Experiente:

Mas a única coisa que eu acho ruim é que tem uma federação que fica te submetendo a ficar só nela. As outras não, as outras deixam você livre, deixa o atleta livre para poder escolher o que ele quiser, para fazer o que ele quiser, subir [no palco] na que ele quiser. Eu acho que o atleta tem que ter o direito de escolher onde ele quer ir, não se federar em uma e ficar ali. Eu acho isso errado! [sic] (Experiente, 2020)

Aqui vemos a defesa pela liberdade do indivíduo (atleta) em escolher em qual competição participar, advogando por uma abertura do mercado de disputas esportivas fisiculturistas, operando, de certa maneira, com a ideia de livre concorrência e de livre escolha. A premissa de liberdade individual, entendida como um valor central da civilização, está na base do neoliberalismo, doutrina político-econômica contemporânea hegemônica no contexto global (e globalizado) que se expressa também nas subjetividades de maneira singular, afetando "tão amplamente os modos de pensamento que se incorporou às maneiras cotidianas de muitas pessoas interpretarem, viverem e compreenderem o mundo" (Harvey, 2005, p. 13).

Algo disso já é possível ver no liberalismo, notadamente aquele que, segundo Foucault (2008, pp. 300-301), é característico dos Estados Unidos e se coloca como "princípio fundador e legitimador do Estado", caracterizando-se mais como um "tipo de relação entre governantes e governados" do que como "uma técnica dos governantes em relação aos governados". Nesse contexto, é fulcral a questão das liberdades dos indivíduos como utopia a ser constantemente reativada, inclusive no registro das práticas comerciais. Talvez não seja mero detalhe observar que os campos nos quais transitam nossas informantes, fisiculturismo e fitness, são também expressão da racionalidade estadunidense impregnada por tal ideologia que, no contemporâneo, engendra um novo sujeito estimulado pela competição e pelo individualismo em busca do sucesso.

Esse espírito parece conformar a subjetividade de nossas atletas empreendedoras - entendidas aqui como mulheres capazes de "detectar uma oportunidade e criar um negócio para capitalizar através dele, assumindo riscos" (Dornelas citado por Gut et al., 
2018, p. 317) - que se habituam a transitar em um mundo narcisista, competitivo e individualista, que abre um campo de possibilidades laborais demarcadas pelo just do it (não à toa um lema que figurou por um longo período como propaganda de uma grande marca esportiva). É importante dizer que esses são projetos mais do que legítimos e que essas mulheres jogam com os elementos que estão disponíveis, fazendo do fisiculturismo um estilo de vida não apenas como atividade esportiva, mas como prática que inunda seus fazeres, gostos e prazeres. E é no mercado das competições que elas aprendem a comprar e vender seus produtos e serviços.

Sobre essa organização, o depoimento de nossa informante Profissional, com experiência em eventos internacionais, especialmente nos EUA, parece ser ilustrativo: "A gente entrava num lugar onde ia ser o campeonato, era uma feira gigante, você abria uma porta, parecia um portal, parecia um estádio tipo o Maracanã. Gigante!”. Tal feira não se restringe apenas aos competidores, mas também a todo público que acompanha a competição, sendo local em que se vende produtos, assim como a própria imagem, espaço para ver e ser visto.

Em pesquisa realizada com fisiculturistas na cidade de Curitiba, Grimm (2017) descreve o local da competição por ela analisada de maneira muito semelhante ao que nossa informante aponta: ambiente onde se misturam atletas, "patrocinadores e comerciantes dos diversos segmentos e setores fitness [que] aproveitavam para divulgar seus produtos que estão constantemente sendo atualizados" (Grimm, 2017, p. 117), indicando as intensas atividades comerciais estabelecidas nos espaços dos campeonatos. Ali vende-se de roupas a aparelhos de musculação, passando por serviços estéticos variados especialmente disponíveis e utilizados pelas atletas no backstage ${ }^{1}$ e que conformam a produção final para o show: ${ }^{2}$ cabelo, maquiagem e pintura corporal.

Se no fisiculturismo "o corpo é o próprio espetáculo" (Jaeger, 2009, p. 177), tudo deve estar em perfeita harmonia para causar o impacto desejado, o que significa que não basta estar com o shape perfeito, é necessário saber mostrá-lo no momento da disputa. Para tanto, gastos com figurino (biquíni e sandália de salto, no caso de algumas categorias), penteado, manicure, maquiagem e pintura corporal (recurso para melhor visualização do desenho muscular) somam-se àqueles cotidianos, como alimentação, suplementação, hormônios etc. Segundo nossas atletas, uma preparação pode custar entre $\mathrm{R} \$ 5 \mathrm{mil}$ a $\mathrm{R} \$ 30 \mathrm{mil}$, considerando ainda deslocamentos e hospedagens. Para aquelas que não têm nenhum tipo de apoio financeiro, apela-se para soluções mais baratas e caseiras:

1 É comum o uso de termos em inglês no vocabulário do campo, provavelmente por conta da influência norte-americana no esporte. 
Em relação aos biquínis, na época que comecei a competir procurei eu mesma fazer, não tinha condições de comprar. Então eu fazia. Ia na menina da loja de roupa perto da academia, ela fazia para mim, botava aqueles brilhinhos japonês, colava no biquíni todinho, e subia com aquilo ali. Mas eu não ia na IFBB, que tinha um padrão de biquíni, né?! (...) Eu mesma me maquiava, fazia meu cabelo, eu dava meu jeito! [sic] (Experiente, 2020)

Se essas estratégias funcionam no circuito amador, no profissionalizado o sistema é diferente. Não é apenas o biquíni que é padronizado, como apontou a informante na fala acima, mas também a preparação para o palco, que deve ser feita com a organização do evento, notadamente os internacionais, em que os jurados estão atentos a cada detalhe. Segundo relatou a Profissional: "A maquiagem e o cabelo têm que ser feitos sempre com a produção do campeonato, porque se você não faz eles sabem", o que significaria um investimento em torno de US $\$ 400,00$ somente no contexto do backstage, segundo ela.

Tanta despesa com embelezamento para apresentação de palco tem justifica mais do que legítima no campo, já que é esse o momento de exibir da melhor maneira possível a modelação corporal, por meio tanto de gestualidade peculiar, que permite a visualização dos desenhos musculares (através de desfile, de um conjunto de poses compulsórias e, em alguns casos, de coreografias de dança), quanto dos artifícios estéticos que destaquem a atleta e a façam "brilhar bem, [porque] você tem que chamar atenção, tem que subir no palco e chamar atenção, pegar a atenção toda para você! Lá você se vende, você se joga, você quer ter a melhor performance". [sic] (Experiente, 2020)

Chama a atenção o termo "vender-se", expressão que se fez presente em diferentes momentos nas falas de nossas atletas, o que parece indicar um discurso, mas especialmente uma mentalidade, marcada pelo comércio, em que essas mulheres falam de seus corpos como produtos a serem vendidos-comprados. Porém, essa mercadoria não se configura como algo literal, mas o que se vende (e compra) é uma imagem e uma promessa: a imagem de um corpo milimetricamente moldado, potente e vencedor; a promessa de que todas podem igualmente ser como elas, basta querer. Nesse cruzamento é que nossas informantes vão estabelecendo suas estratégias, vendendo-se como atletas e como profissionais fitness.

No primeiro caso, têm-se as maneiras de se manter no auge do rendimento e com visibilidade no esporte. No segundo, observam-se as formas de ressignificar a expertise atlética em serviços voltados para um estilo de vida que preconiza a saúde, o bem-estar e a beleza. Entender como essas mulheres operam tais articulações e configuram seus campos de atuação profissional é o que faremos na sequência. 


\section{Mercado de trabalho:}

\section{ser atleta e ser empreendedora}

Podemos dizer que nossas entrevistadas estabelecem certa distinção entre suas carreiras: há, por um lado, o ofício de atleta, com sua rotina de treinos, dieta e competições e, por outro, a atividade em academias de musculação - mas também e cada vez mais na internet -, como instrutoras, personal trainers, preparadoras de atletas e até mesmo coaches. Ambos se inscrevem no mundo do trabalho, ganham contornos e sentidos diversos e se imbricam enquanto projetos de vida, havendo clara influência do fisiculturismo em suas escolhas e estratégias profissionais.

No caso do esporte, ele não aparece estritamente como um trabalho, apesar de ser considerado uma carreira. As horas gastas dentro da academia moldando os músculos não compõem, no registro subjetivo dessas atletas, ocupação laboral. Inclusive, as sessões de treinamento/musculação são organizadas a partir dos horários profissionais de cada uma delas, o que se refere às atividades pelas quais recebem algum pagamento: "A gente tem que priorizar o trabalho, então quando dava a gente encaixava o nosso treino" (Profissional, 2020).

Mas há aqui estratégias de manutenção no mercado de disputas fisiculturistas, convertidos não em ganhos monetários, mas em produtos e serviços que auxiliam no rendimento das atletas. Tais recursos variam conforme o nível de inserção na prática esportiva, oscilando entre um caráter profissionalizado e outro amadorístico. No caso da atleta Profissional, sua busca é por apoio financeiro oriundo de patrocínios e parcerias com empresas, já a Experiente representa a questão de um ponto de vista pouco institucional, conferindo o sentido de ajuda personificada (na figura da pessoa) a qualquer suporte pecuniário que venha a receber. Dizem elas:

Tenho patrocínio, tenho parcerias. Na verdade, desde que comecei a competir, passado os primeiros anos, consegui fechar logo com uma empresa (...) Sempre fui uma atleta que busquei patrocínio. Quando é patrocínio, é patrocínio real, porque meu objetivo era competir nos EUA, para ser profissional. (...) Tem empresas-parceiras que estão comigo há 5 anos, que estão sempre me ajudando, o ano todo, em todos os campeonatos. Se eu vou fazer um evento eles estão comigo, qualquer coisa que eu precisar estão comigo, então são parceiros-patrocínios. [sic] (Profissional, 2020)

Hoje em dia, como eu falei, as coisas estão mais fáceis para mim, tem umas pessoas que estão me ajudando. (...) Eles que pagaram tudo na preparação para o Brasileiro, foram quase $\mathrm{R} \$ 5 \mathrm{mil}$. Tudo, desde a cinta que eu comprei até a passagem de 
ida e volta. (...) Mais gasto com hormônio. (...) Aí vem biquíni, hospedagem, alimentação... Eles estão me ajudando com tudo. (Experiente, 2020)

Há claramente aí uma distinção na forma de observar a carreira esportiva e traçar seus planos de ação e investimento. A atleta Profissional incorpora uma mentalidade profissionalizada de sua carreira nos palcos, enquanto a Experiente coloca o fisiculturismo em outro lugar, como uma oportunidade de desenvolver seu trabalho na área fitness.

Eu boto primeiro meus estudos [como prioridade], eu acho que tenho que investir na minha carreira. Isso aí sim vai me levar além! Não que eu não tenha ganhado muita coisa com o fisiculturismo. Ganhei! O meu bacharelado, ganhei um desconto no último ano por causa do fisiculturismo. Ganhei pós-graduação, ganhei muita coisa! [sic] (Experiente, 2020)

Essa expertise adquirida durante anos dentro das academias de musculação e, mais importante, a forma corporal obtida com esse trabalho tornam-se uma porta de entrada no mercado fitness. Nesse processo, essas mulheres se tornam, por um lado, empresárias da própria aparência, ao "identificar as oportunidades para otimizar a performance física, [concebendo] o corpo como um ente carente de investimentos" (Sant'Anna, 2014, p. 181, grifos no original), bem como empresárias da aparência e performance corporal, vendendo serviços.

0 primeiro deles é o de personal trainer, que parece ser o caminho mais comum e desejado na área fitness. 0 atendimento especializado e individualizado na prescrição e orientação de exercícios físicos com vistas à manutenção da saúde e/ou modelação corporal incorpora a lógica empresarial personificada num único indivíduo, ocupado em vender "serviços de aptidão e (...) conquistar o cliente, satisfazê-lo e mantê-lo fiel" (Bossle, 2008, p. 187). Tal profissional pode ser pensado então como uma "super microempresa" formada por "uma só pessoa, sem vínculos empregatícios, sem local específico de trabalho que precisa dar conta de sua demanda profissional e se preocupar em demarcar seu território no mercado da atividade física" (Bossle e Fraga, 2001, p. 155).

Se a escolha pela Educação Física e o trabalho nas academias de musculação, especialmente como personal trainer, é o passo mais comum na reconversão dessas atletas, identificamos ainda outros serviços por elas disponibilizados e desenvolvidos, alguns ligados ao mercado do fisiculturismo, outros ao do fitness e bem-estar. No primeiro caso, encontramos dois exemplos: o de treinadora de novos atletas do esporte e o de preparadora para palco. 0 primeiro se coloca como uma espécie de desenvolvimento do trabalho já realizado como personal trainer na academia, quando identificam uma potencial fisiculturista, como apontou a Experiente (2020): "Umas alunas a gente vê e 
pensa: 'Pô, essa menina dá uma boa Bikini!' Eu tento incentivar ela a competir, porque ela também já gosta, então eu incentivo a competir" [sic].

O exemplo da preparação para o palco talvez seja o que melhor expressa o caráter empreendedor no sentido da criação de um novo serviço, ao perceber uma falta no mercado. Isso é o que nos relata a atleta Profissional, ao descrever o desenvolvimento de sua função como professora de pose e desfile:

Eu tenho muita desenvoltura para o palco, nunca tive timidez para o palco, já tinha feito aula de dança, aula de desfile... Particularmente poso fluentemente bem no palco, faço uma boa transição de poses e começou a ter interesse das meninas em fazer aula de pose comigo, e vi que era mais uma forma de trabalhar, de estar dentro do esporte. Eu comecei a dar aula de pose, apresentação, desfile para as categorias Wellness, Bikini e Figure. Então também faço esse trabalho, tanto presencial quanto online, no celular, puxa uma câmera e faz. Tanto no Brasil como fora do país, mesma coisa, assessoria online. Foi mais um pedaço do mercado que comecei a trabalhar com relação aos fortes. (Profissional, 2020)

No excerto podem-se perceber algumas características do que se costuma chamar de empreendedorismo. Segundo Gut et al. (2018), seus principais aspectos são: iniciativa para criar um novo negócio, utilização de recursos disponíveis de maneira criativa e a disponibilidade para assumir riscos. Analisando o discurso da Profissional, notamos sua capacidade de transformar uma habilidade esportiva fundamental no caso do fisiculturismo, o posar, em um serviço especializado e, ao menos por algum tempo, quase exclusivo, alcançando até mesmo o contexto internacional. Sua criatividade não se expressa só na elaboração da mercadoria (aulas de pose), mas também nas técnicas de venda dessa mercadoria, como a assessoria on-line, algo que cresceu exponencialmente depois da pandemia de covid-19, mas já era uma realidade de nossa informante, segundo seu relato. Seu movimento é o de expandir o mercado fisiculturista para nele se manter.

O ideal empreendedor parece bem coadunar com essas mulheres que modelam suas subjetividades (assim como seus músculos), a partir da incorporação de códigos e preceitos que, de certa maneira, podem ser também vistos no espírito do empreendedorismo. Talvez não seja sem sentido dizer que há algo de esportivo no comportamento daquele que empreende e algo de neoliberal no esporte. Se as características do empreendedor podem ser definidas como busca de oportunidades e iniciativa, disposição para correr riscos calculados, persistência, exigência de qualidade e eficiência, comprometimento, busca de informações, estabelecimento de metas, planejamento e monitoramento sistemáticos, persuasão e redes de contato, independência e autoconfiança (Gut et al., 2018), constatamos que as fisiculturistas pesquisadas aprendem tais atributos no 
cotidiano do seu trabalho como atletas, já que o processo de modelação muscular e preparação para a competição articula, de maneira mais ou menos evidente, tais elementos.

Questões como persistência nas adversidades, exigência de qualidade e eficiência máxima nos treinos e competições, comprometimento com o projeto esportivo, estabelecimento de metas corporais e competitivas, planejamento e monitoramento do trabalho e dos resultados, independência e autoconfiança no seu rendimento e na sua capacidade de autossuperação, além da visão do esporte como um campo de oportunidades são comuns na vida de atletas. Além disso, particularmente entre as fisiculturistas investigadas, constatamos também alto grau de riscos (calculados) nos experimentos corporais que produzem a forma hiperbólica desejada (particularmente na articulação de dietas extremas e manipulação de esteroides anabolizantes), busca de informações para aprimoramento da performance, na medida em que, muitas vezes, é um trabalho solitário, sem supervisão de treinadores (o que exige a mobilização de conhecimentos e saberes técnicos por parte das atletas) ${ }^{3}$ e relevância das redes de contato, especialmente nas competições profissionais. ${ }^{4}$

Assim, haveria a conformação de uma subjetividade atlética fisiculturista correspondente a uma subjetividade empreendedora, manifestação contemporânea do mundo do trabalho em que a ideologia da performance, que tem no esporte seu maior exemplo, prevalece. Nesse sentido, o ideal esportivo torna-se parâmetro também para a esfera da produção e do consumo, na medida em que a concorrência passa a ser vista como competição e o indivíduo como herói que produz com crescente eficiência e velocidade (Ehrenberg, 2010). No caso por nós pesquisado, encontramos, inclusive, a articulação de todo um vocabulário do mundo empresarial na fala de nossas entrevistadas, como mercado, vender, marketing, coach.

Sobre o último, para além da utilização no campo do termo em inglês para denotar a função do treinador e/ou técnico, há ainda o desenvolvimento de um discurso que se aproxima do coaching, método comportamental cada vez mais em voga no mundo business que atua no âmbito do gerenciamento de pessoas com vistas a um melhor desempenho dos indivíduos. Mas os coaches não se restringem apenas ao contexto profissional e invadem os territórios mais íntimos da vida, como a família, os relacionamentos amorosos e também a modelação corporal, seja no campo esportivo, do emagrecimento e/ou da nutrição.

É nesse segmento que nossas atletas atuam, não apenas com seu conhecimento técnico e científico, seus saberes atléticos e profissionais, mas também com a propagação de

3 Destaque para o caso da Experiente que afirmou ter realizado um curso de farmacologia para aprender mais sobre manipulação de hormônios.

4 Questão apontada pela Profissional ao indicar que as redes de contato (a exemplo dos juízes) no contexto do fisiculturismo profissionalizado são importantes para o estabelecimento de estratégias de apresentação no palco, o que não significa determinação a priori dos resultados. 
um discurso da perseverança, da necessidade de ser forte e combativo na vida, de ver o lado positivo das coisas e pensar sempre na solução dos problemas colocados pela realidade. Esse discurso também é modelado pelos anos de prática de uma modalidade que proporciona ao corpo e à subjetividade experiências radicais, inculcando a ideia de que somente o indivíduo mais bem preparado, o que se submete ao trabalho exaustivo sem esmorecer, pode sair vitorioso: "Eu sempre gosto de ver o lado bom da coisa. Você me dá um problema, eu arrumo a solução. (...) Então acordou, você tem um dia pela frente, ou você engole ele ou ele vai te engolir. Você escolhe!" (Profissional, 2020).

Por fim, a ideia de marketing foi mobilizada pelas atletas como sinônimo de autopropaganda, no esporte e nos serviços, com intuito de "vender-se", de seguir "na mídia", segundo nos disse uma das entrevistadas. Para tanto, o uso das redes sociais, espaços virtuais cada vez mais significativos na veiculação das imagens e dos chamados conteúdos a elas vinculados, pareceu singular. Nesse cenário, formas de utilização dos recursos digitais são pensadas de acordo com o objetivo e o público que se quer atingir: "Eu não usava Instagram! Quando eu fui competir, muita gente me orientou a usar o Instagram. (...) Para vender a minha imagem como atleta, o Instagram ajuda muito! (...) Mas o meu perfil profissional é mais no Facebook!" [sic] (Experiente, 2020).

A Experiente mostra que há redes distintas para cada carreira; na atlética, o Instagram seria mais vendável, enquanto que, na profissional (prestadora de serviço), o Facebook se mostraria mais eficiente. Segundo dados do relatório global digital de outubro de 2020, produzido pelas empresas We Are Social e Hootsuite, o Facebook foi a rede mais utilizada no Brasil naquele ano (130 milhões de contas), já o Instagram seria a quarta mais acessada pelos brasileiros (95 milhões), ficando atrás ainda do WhatsApp e do YouTube (Volpato, 2021). 0 formato dessas plataformas também é um elemento a ser considerado, se o Facebook é mais "versátil e abrangente, [pois] reúne muitas funcionalidades no mesmo lugar" (Volpato, 2021), servindo não apenas para relacionamento com amigos e familiares, mas também para gerir negócios, o Instagram é mais circunscrito à veiculação de imagens (fotos e vídeos) e configurado para utilização em dispositivos móveis (mesmo podendo ser acessado em desktops), o que pode restringir sua operacionalização.

Se para divulgação do perfil de atleta o Instagram é a rede mais adequada - notadamente de um esporte que tem como centralidade a exibição da forma corporal hiperbólica -, é preciso saber utilizá-la da maneira mais eficiente para se diferenciar dentro de um novo mercado que se estabelece no contexto virtual. 0 aumento de influenciadoras digitais que se dedicam ao tema da modelação corporal, as chamadas musas fitness, ou "blogueirinhas", conforme apontam as fisiculturistas, coloca certa tensão no campo, na medida em que pode comprometer a imagem tanto do esporte quanto do trabalho especializado na área fitness, justamente pelo fato de elas não serem profissionais. Para lidar com essa questão, nossas informantes investem em formação e na produção de 
conteúdos que, segundo pensam, possam ser um diferencial na vida de mulheres reais dispostas a mudar seus corpos e seu estilo de vida. Se para as influenciadoras digitais o Instagram é o fim, enquanto espaço de "venda" de si mesmas, para nossas entrevistadas é um meio, lugar de propaganda da dupla carreira que administram, de atletas e de prestadoras de serviços do mundo fitness.

Eu sempre me preocupei em levar conteúdo. Claro que você quer postar uma foto bonita também, né? Você quer postar uma coisa bacana, mas sempre me preocupei em levar conteúdo, porque foto bonita todo mundo tem. Mas chega uma hora que se você não tiver conteúdo, se você não tiver o que falar, esquece! (...) Uma foto bonita vai alcançar milhões de pessoas, mas é só mais uma foto, a pessoa vai curtir e vai passar, mas se aquele conteúdo alguém leu, me deu um feedback, aquilo chegou para alguém de outra forma, te separa um pouco. Primeiro, não sou blogueira, não vivo de Instagram para fazer só foto... É para levar informação, levar conteúdo (...) 0 legado que você vai deixar é o que você fala, o que você prega [sic]. (Profissional, 2020)

\section{Algumas considerações}

No contexto econômico contemporâneo, constatamos um sem-número de dispositivos que incidem tanto sobre a dimensão objetiva da vida como a subjetiva, na medida em que o neoliberalismo se expressa nas relações de mercado assim como nos modos de pensar e ver o mundo (Harvey, 2005). Nessa engrenagem, os cuidados com o corpo compõem elemento singular, visto que a aparência corporal se transforma também em valor, a partir de um discurso normatizador que determina como deve ser o corpo ideal do sujeito bem-sucedido (Águila et al., 2020).

A constituição de um mercado fitness que vende produtos e serviços que prometem beleza, saúde e bem-estar alinha-se a uma mentalidade que incita ao consumo, responsabilizando individualmente cada pessoa por sua forma corporal e seu estilo de vida. Um corpo esbelto, forte, potente externaria um espírito produtivo, combativo e ativo, pronto para o mundo do trabalho, símbolo do sujeito disposto a se destacar e fazer a diferença na sociedade, confirmando a promessa (nunca cumprida) de que o capitalismo é democrático e o sucesso pode ser alcançado por todos, basta querer e fazer.

Entre fisiculturistas encontramos uma subjetividade alinhada a tal discurso e prática, em que a corporeidade se apresenta como mercadoria rentável não apenas como consumidoras, mas também como produtoras e vendedoras, representantes, podemos dizer, do homo oeconomicus do neoliberalismo, não mais entendido como parceiro de troca, mas 
como "empresário de si mesmo, sendo ele próprio seu capital, sendo para si mesmo seu produtor, sendo para si mesmo a fonte de [sua] renda" (Foucault, 2008, p. 311).

O espírito neoliberal empreendedor se expressa nas mulheres investigadas na mobilização de seu capital-corpo, de sua experiência e conhecimento (prático e teórico) na área da modelação corporal, para produção de novos produtos e serviços voltados ao mercado da beleza, da saúde e do bem-estar. Vale ainda destacar que empreender pode significar um meio de ascensão social, algo constatado no caso de nossa atleta Experiente que, antes de ser fisiculturista, trabalhava como faxineira na academia onde atualmente atua como professora e personal trainer. 0 esporte lhe proporcionou uma forma de ascender, não exatamente nele (já que os ganhos pecuniários no fisiculturismo no Brasil são ínfimos), mas como um desdobramento dele (abrindo um campo de possibilidades laborais na área fitness).

Entendemos que o fisiculturismo conforma uma mentalidade de autorresponsabilização dos indivíduos não só pela sua saúde e pela sua forma corporal, mas também pela sua capacidade de ganhar dinheiro. Se "vender-se" no palco é mandatório para vencer uma competição, criar novas alternativas de vendas é igualmente necessário para permanecer no mercado fisiculturista/fitness, algo que nossas entrevistadas demonstram saber fazer.

\section{Referências bibliográficas}

Associação Brasileira de Academias. (2018). IHRSA publica dados do mercado mundial do fitness. Revista ACAD Brasil, 20(82), 10-20. Recuperado de https://www.acadbrasil.com.br/wp-content/uploads/2019/03/edicao-82.pdf. Acesso em 27/08/2020.

Águila, C., Sicilia, Á., e Segovia, L. (2020). El ideal de cuerpo delgado y la formación del sujeto neoliberal: Un estudio de caso. Movimento, 26(e26084), 1-23. Recuperado de https://seer.ufrgs.br/Movimento/article/view/104124.

Bossle, C. B. (2008). o personal trainer e o cuidado de si: Uma perspectiva de mediação profissional. Movimento, 14(1), 187-198. Recuperado de https://seer.ufrgs.br/ Movimento/article/view/3764.

Bossle, C. B., e Fraga, A. B. (2011). 0 personal trainer na perspectiva do marketing. Revista Brasileira de Ciências do Esporte, 33(1), 149-162. Recuperado de https://www.scielo.br/scielo.php?pid=S010132892011000100010\&script=sci_abstract\&tlng=pt.

Carmo, L. J. O., Assis, L. B., Gomes Junior, A. B., e Teixeira, M. B. M. (2021). 0 empreendedorismo como uma ideologia neoliberal. Cadernos EBAPE.BR, 19(1), 18-31. Recuperado de http://bibliotecadigital.fgv.br/ojs/index.php/cadernosebape/article/ view/83118/78967. 
Ehrenberg, A. (2010). O culto da performance: Da aventura empreendedora à depressão nervosa. São Paulo: Ideias \& Letras.

Foucault, M. (2008). Nascimento da biopolítica. São Paulo: Martins Fontes.

Gonçalves, R. (2012). Novo desenvolvimentismo e liberalismo enraizado. Serviço Social \& Sociedade, 112, 637-671. Recuperado de https://www.scielo.br/j/sssoc/a/ 35tRSzsTBxzLLgmThm3rvVF/?lang=pt\&format=pdf.

Grimm, G. C. (2017). Hardcore ladies: O fisiculturismo de mulheres (Dissertação de Mestrado). Universidade Federal do Paraná, Curitiba. Recuperado de https://acervodigital.ufpr.br/handle/1884/55762.

Gut, B. C. P., Santos, M. S., e Oliveira, E. M. J. (2018). A mulher empreendedora e o delineamento do perfil profissional da personal trainer. Id on line: Revista de Psicologia, 12(40), 315-335. Recuperado de https://idonline.emnuvens.com.br/id/article/view/1015.

Harvey, D. (2005). O neoliberalismo: História e implicações. São Paulo: Loyola.

Jaeger, A. A. (2009). Mulheres atletas da potencialização muscular e a construção de arquiteturas corporais no fisiculturismo (Tese de Doutorado). Universidade Federal do Rio Grande do Sul, Porto Alegre. Recuperado de https://www.lume.ufrgs.br/ handle/10183/15749.

Landa, M. I. (2011). Las tramas culturales del Fitness em Argentina: Los cuerpos activos del ethos empresarial emergente (Tese de Doutorado). Universitat Autònoma de Barcelona, Barcelona. Recuperado de https://www.tdx.cat/bitstream/handle/10803/42294/mil1de3.pdf.

Lima, M. S. (2017). "Foco, força, fé": uma etnografia sobre o fisiculturismo feminino em Salvador-BA (Dissertação de Mestrado). Universidade Federal da Bahia, Salvador. Recuperado de https://repositorio.ufba.br/ri/handle/ri/26212.

Sant'Anna, D. B. (2014). História da beleza no Brasil. São Paulo: Contexto.

Schwengber, M. S. V., Brachtvogel, C. M., e Carvalho, R. S. (2018). Espraiamento discursivo da cultura do fitness na contemporaneidade. Movimento, 24(4), 1167-1178. Recuperado de https://seer.ufrgs.br/Movimento/article/view/83071/51803.

Vieira, C. L. N., e Vaz, A. F. (2014). Formação docente em educação física e o esporte: Os jogos internos/integração de educação física/UFSC. Educación Física y Deporte, 33(2), 287-311. Recuperado de https://revistas.udea.edu.co/index.php/educacionfisicaydeporte/article/view/23467/20747. Acesso em 04/09/2020.

Volpato, B. (2021, 11 de janeiro). Ranking das redes sociais 2020: As mais usadas no Brasil e no mundo, insights e materiais gratuitos. Resultados digitais. Recuperado de https://resultadosdigitais.com.br/blog/redes-sociais-mais-usadas-no-brasil/.

Wacquant, L. (2002). Corpo e alma: Notas etnográficas de um aprendiz de boxe. Rio de Janeiro: Relume Dumará. 